\title{
Workplace beliefs about luck among taiwanese nurses
}

Fang-Yi Lin*, Hung-Ru Lin and Tzu-Ying Lee

*Correspondence: fangyi@ntunhs.edu.tw

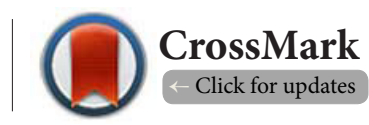

Department of Nursing, School of Nursing, National Taipei University of Nursing and Health Sciences, Taipei, Taiwan, Republic of China.

\begin{abstract}
In today's science driven healthcare environment, although evidence-based information is increasingly used to guide clinical decision making, irrational beliefs are still prevalent among nurses.

Purpose: The purpose of this study is to increase understanding of workplace-related beliefs about luck and its varied meanings among nurses in Taiwan.

Method: A qualitative design was conducted using a content analysis approach. This paper is a description of inductive and deductive content analysis.

Findings: These findings represent twelve general examples of workplace-related beliefs on good luck and bad luck among Taiwanese nurses. The author of this study uncovered the complexity and sometimes irrationality of human nature and behavior in a hospital context. All beliefs have their own meanings.

Implications: These irrational beliefs are long-forgotten ways of thought that affect nurses still. We suggest that discovering nurses' viewpoints and cultural ideals is important to understand nursing practices. Nurses should be aware and understand these beliefs cautiously, and not rely too much on luck.
\end{abstract}

Keywords: Workplace beliefs, luck, nurses, mental health

\section{Introduction}

\section{Statement and significance of the problem}

A study by Day and Maltby (2003) shows that perceptions of being lucky are associated with better mental health, while perceptions of being unlucky are associated with poorer mental health [1-3]. Workplace-related beliefs about luck can be cultivated in the present time or drawn from experiences in the individual or collective past. These include carrying a lucky charm [4] or crossing their fingers [5]. Although many people claim that they aren't superstitious, workplace-related beliefs about luck actually plays a significant part in our lives. In Taiwan, there are still a few implicit hospital taboos that one is not supposed to do. There are also workplace-related beliefs and practices that medical staff specifically follow to bring luck. Initially, the author was made aware of hospital superstitions through Facebook posted by nurses or nursing students. In fact, the course of some people's lives has been influenced by such workplace-related beliefs. This study is intended to present a list of representative workplace-related beliefs regarding luck in Taiwanese nurses.

\section{Literature review}

Despite their prevalence, workplace-related beliefs around luck are largely unstudied based on the evidence presented in the professional literature. A short review of the literature on beliefs about luck for healthcare professionals as follows.

\section{Beliefs about luck among healthcare practitioners}

Beliefs about luck can affect actions that health professionals take in relation to health, disease, and treatment. Application of luck and beliefs about luck has significance for nurses, their sense of control, their competence, and their empowerment [6]. Many medical professionals believe in superstition [7]. Researchers conducted a study to determine the prevalence of work-related superstitions among perioperative nurses [8]. Scholars indicated that $23 \%$ of respondents view themselves as generally superstitious, and that certain specific workrelated superstitions are widespread. A study showed more than $40 \%$ of the medical staff is convinced that lunar phases affect human behavior [9]. Another irrational belief implies that leaving hospital on a Saturday is bad luck and $40 \%$ of doctors would allow postponement of discharge based on the patients' superstitions [10].

In Western legends, superstitions associated with bad luck include the date of Friday the $13^{\text {th }}$ [11] and the medical professionals who work on those dates hold all kinds of beliefs. Some 
Lin et al. Journal of Nursing 2014,

hospitals in Western countries may not have a $13^{\text {th }}$ floor. However, a study by Kumar, Kumar and Isaacson (2004) reported that post-tonsillectomy hemorrhages do not occur more frequently in redheaded children or on Friday the $13^{\text {th }}$ days [12]. Szasz (2011) indicated that irrational beliefs, brooding, and reflective thinking are related to distress, and that the impact of irrational beliefs on distress is completely mediated by brooding [13]. Healthcare professionals should learn these phenomena from our workplace and be thoroughly informed.

\section{Theoretical background}

According to Response Expectancy Theory, expectancies can directly alter our subjective experience of internal states [14]. Researchers have long known that expectations influence cognition and behavior. Once people anticipate that a specific outcome will occur, those expectancies increase the probability of automatic responses that we assume to be habitual cognitive responses [15].

Psychological research on irrational belief has mostly focused on how performing a superstitious ritual helps people gain a sense of control. Recent research suggests that superstitions can also exert persuasion on duty performance. For instance, when nervous about an approaching task at work, taking along a lucky charm might increase self-confidence and selfcontrol. Researchers have deliberated on whether or not believing in superstitions also regulates psychological tension and creates a feeling of control and a sense of predictability in otherwise chaotic environments [16-18]. Research has also shown that some individuals believe luck to be a personal attribute, which is internal, stable, predictable, and controllable $[2,3]$. Superstitions are often culturally defined; the underlying psychological processes that give rise to them may be culturally transmitted [19]. It is also possible that the extra effort invested into the execution of superstitions may turn into an advantage for the individuals concerned, and therefore the superstitions continue to persist and remain popular in many societies [20]. Evidence shows that irrational beliefs about luck can have a positive impact on cognition and behavior. These have to work their way into our assumptions to integrate into our mind-maps and shape our values.

\section{Measurement of belief in luck}

In theory, the Belief in Good Luck (BIGL) scale as measured by Darke and Freedman assesses the degree to which individuals believe that luck is a stable quality that they own, versus random and beyond their control $[2,3]$. Andre (2006) developed a four component model of belief in luck and fortune suggesting that belief in good luck and belief in bad luck comprise two separate components [21]. Maltby et al., (2008) proposed a 6-dimensional model of beliefs around luck, as well as an empirically supported model. However, this tool does not encapsulate all aspects of attitudes and beliefs around luck [22]. These studies presented measures of beliefs around luck. Fluke, Webster and Saucier (2012) developed an improved
Belief in Superstition Scale (BSS). Results indicate that the BSS is a valuable research on superstitious attitudes and behavior [23]. Yet superstitious, magical, paranormal, supernatural, and religious beliefs are at least partly overlapping. Lindeman and Svedholm, (2012) further suggested that researchers sharpen the content of these measures and endeavor to integrate different lines of research [24].

\section{Materials and methods}

This research explores these phenomena by collecting work place-related beliefs about luck in Taiwanese nurses and identifying their meanings. Data was collected during October 2012 to September 2013. Narrative information was collected from online interactive forums $[\mathbf{2 5}, \mathbf{2 6}]$. And then researchers conducted the qualitative content analysis process to analysis qualitative data [27].

For the purpose of this study, researchers posted a question, and the informants of this study voluntarily made a statement explaining their beliefs and behaviors around good luck and bad luck in their clinical workplaces. This forum included a discussion board so that nurses and nursing students can discuss their thoughts with each other. This study explored the issue through internet discussion forums where anyone can leave notes and see responses that other people have left. The authors of this study only read and collected from such discussion boards these beliefs about luck in the healthcare workplace.

Analysis of the case study within the cultural context Many Taiwanese beliefs about luck in healthcare settings are connected with food. Typically, they are performed in the context of a work task with the need to obtain good luck or avoid bad luck. The following examples confirm the fact that even people in hospital contexts have their own personal opinions and superstitions. It also serves to demonstrate the relevance of the larger culture and how it effects superstitious beliefs. Here are some examples of such nursing superstitions and behavior in Taiwan (see Table 1).

\section{Not eating pineapples at work}

The pineapple is the number one enemy of nurses. The word pineapple has meaning 'prosperity' that is interpreted as patients having problems. Legend has it that once nursing student's start nursing school, seniors remind student nurses during their internship periods not to eat pineapples in the hospital. As soon as the article "Pineapple Taboo: Myth or Reality" was published in Taiwan Medical Journal, it was uploaded on Facebook, and soon became widely discussed by medical and nursing staff. Some responded that:

"I believe that the pineapple is likely the most cursed fruit. As I know, medical and nursing staffs not only fear the power of the pineapple itself, but also stay away from pineapple cake. They just won't touch anything pineapple related, even if it comes from a well-known store, or even if it is homemade. 
Lin et al. Journal of Nursing 2014,

http://www.hoajonline.com/journals/pdf/2056-9157-1-1.pdf

Table 1. Nurses' workplace-related beliefs and meanings about luck in Taiwanese.

\begin{tabular}{|c|c|c|}
\hline Legends going around hospitals & Meaning and Significance & \\
\hline Not eating pineapples at work & $\begin{array}{l}\text { Medical and nursing staffs generally associate the pineapple fruit with } \\
\text { "abundance", "substantiality", and "prosperity", thus the hectic schedule at } \\
\text { work. }\end{array}$ & \multirow{10}{*}{$\begin{array}{l}\text { The implication } \\
\text { behind food or speech } \\
\text { related taboos is the } \\
\text { wish to have peace at } \\
\text { work (stability of } \\
\text { patients' condition), } \\
\text { and hope that } \\
\text { unexpected situations } \\
\text { outside the norm will } \\
\text { not take place. }\end{array}$} \\
\hline Not eating mangoes at work & "Mango" sounds like "busy" in Chinese. & \\
\hline $\begin{array}{l}\text { Offering "Kuai Kuai Corn/Coconut } \\
\text { Snack" in green packaging in Ghost } \\
\text { "Putu" Festival }\end{array}$ & It means patients will "behave", and green signifies a sense of security. & \\
\hline $\begin{array}{l}\text { Not drinking "Daily C" juice at } \\
\text { work }\end{array}$ & $\begin{array}{l}\text { C represents CPR, so drinking "Daily C" means having patients requiring } \\
\text { CPR everyday. }\end{array}$ & \\
\hline Not eating beef at work & $\begin{array}{l}\text { Cattle represent diligence and hard work, so eating beef means working } \\
\text { like a cow. }\end{array}$ & \\
\hline $\begin{array}{l}\text { Staying away from "bad luck" } \\
\text { colleagues }\end{array}$ & $\begin{array}{l}\text { Some people bring "bad luck", so working with them means being dragged } \\
\text { down. }\end{array}$ & \\
\hline $\begin{array}{l}\text { Never say you are "not busy" before } \\
\text { getting off work. }\end{array}$ & Once you said it, you will weirdly get really busy. & \\
\hline Do not ink seals at work & $\begin{array}{l}\text { It means you will have "lots of seals to stamp" and get really busy. Seeing } \\
\text { red ink means "seeing blood." }\end{array}$ & \\
\hline $\begin{array}{l}\text { Always turn over the mattress after } \\
\text { someone passed away }\end{array}$ & $\begin{array}{l}\text { To let the deceased know the bed he or she slept in has been moved } \\
\text { somewhere else. Without doing so, the deceased will take the life of the } \\
\text { next patient. }\end{array}$ & \\
\hline $\begin{array}{l}\text { Do not say "see you again" upon } \\
\text { parting in the hospital }\end{array}$ & $\begin{array}{l}\text { Patients do not want to hear "see you again" from nurses, meaning they will } \\
\text { return to the hospital someday. }\end{array}$ & \\
\hline $\begin{array}{l}\text { The nurse's cap is a sign to keep } \\
\text { demons away }\end{array}$ & Wearing the nurse's cap for keep demons away. & $\begin{array}{l}\text { Demons will not dare } \\
\text { get close. }\end{array}$ \\
\hline $\begin{array}{l}\text { Hospital elevators skip on the fourth } \\
\text { floor or No. } 4 \text { ward }\end{array}$ & "Four" in Chinese pronounce sounds the same as "death." & It is unlucky. \\
\hline
\end{tabular}

If you think it won't hurt eating cookies made from pineapple, think again. Researchers should include ER personnel in their research to derive more accurate results."

\section{Not eating mangoes at work}

Another practice is that nurses do not eat mangoes at work, because when pronounced in Chinese, mango sounds like "busy". One respondent said.

"It has more to do with people. People who are laid back can eat as much mango as they want and feel good about it."

\section{Offering "kuai kuai corn/coconut snack" in green packaging in ghost "putu" festival}

Ghost "Putu" Festival, a popular occasion celebrated throughout China on the 15th day of the seventh lunar month. Ghost "Putu" Festival is passed by slaughtering food, which together with a prodigious table of wine and meat is offered to ghosts from the underworld. Numerous "Putu" festivities are also held at hospital. Taiwanese nurses do actions to try to avoid bad luck, but offering "Kuai Kuai Corn/Coconut Snacks" in Ghost Festival means that they will try to attract good luck.

"I think that if you believe something will happen, there is a higher chance of it happening. We prefer placing 'Kuai Kuai Corn Snack-Coconut' in green packaging during worship rituals, as it signifies patients will 'behave', and the green color gives people a sense of security."

\section{Not drinking "daily C" juice at work}

Also, nurses will never drink Daily $C$, Orange $C$, or any juice brands with $C$ in the initials. Because $C$ represents $C P R$, drinking "Daily C" means that there will be a patient that requires CPR that day.

"As strange as these taboos may sound, some have actually taken place. Once a colleague left a bottle of 'Daily C' juice that her friend gave her on the computerized drug delivery cart. Soon, a defenseless old lady unplugged herself, while another patient had CPR."

\section{Not eating beef at work}

Taiwan was once an agricultural society, and cattle represented diligence, hard work, perseverance, and toughness. Buffalo were used for pulling vehicles and farm equipment in Asia. As a consequence of this historical association with hard work, medical and nursing staffs do not eat beef noodles or food containing beef while on duty. In Taiwan, while some people are very superstitious and others ignore superstitions, knowledge about such superstitions is widespread. For example, those who do not believe in the power of beef eat it behind their colleagues' backs.

"Nurses avoid eating meals with beef at work so that they won't have to work like a buffalo. When there are many patients on a particular day, or when patients' conditions get worse, the busy colleagues will always try to find the offender, 
Lin et al. Journal of Nursing 2014,

that is, the person who ate beef noodles."

\section{Staying away from "bad luck" colleagues}

Some people believe that some nurses are "bad luck" than others. They believe that they too will become busy when working with this person. Since no one wants to be at work with such people. These colleagues secretly pray that those who "bring about prosperity" (to paraphrase an increased frequency of medical problems or additional work) do not shuttle through their wards and that their names do not appear on the assignment whiteboard.

"Whenever these people go to work, patient problems or ER events will significantly increase, and even bringing amulets will not be much help. Some people are consistently unlucky and 'bring prosperity' to work, even without the influence of food. And others are just lucky. Whenever these kinds of people come to work, like "You-Know-Who" in the Harry Potter series, only their phone numbers or codes instead of their names will appear on the whiteboard for registered shifts."

\section{Never say you are "not busy" before getting off work}

Nurses are habitually watchful about the words they use. Because the minute you speak those words or think those thoughts, this may cause bad fortune. If ward patients are calm and there is not much work to do, avoid saying "I'm not busy". Should one actually communicate that, and then they might actually get really busy, is the response most nurses will give. Unexpected events can happen just when someone least expects them to. Nurses on duty do not like to be asked how they are doing. For example, if someone asks "How's the day been so far?" they will avoid replying "It's been a calm day", because then they will almost surely be blamed for the sudden onrush of work that will follow. "Stop talking about it." Is what they will communicate instead.

\section{Do not stamp seals at work}

Whenever red ink for officially stamping documents runs out, it is refilled during off-duty hours to avoid "seeing blood." Seals used at work should not be refilled during work hours. "I don't ink the seals before work, or else I will have seals to stamp all day, because this means that there will be seals to stamp all day long and endless patient related problems to take care of. Or otherwise your unit will get new admission after ad mission."

\footnotetext{
Always turn over the mattress after someone passes away Nurses always hope that someone passes away never happen while they are on duty. One example of a superstition that has become common during nursing practice refers to the bed that someone dies in. According to belief, if a patient dies in a particular sickbed, after disinfecting the bed, the mattress should be turned over and new sheets are laid. This action refers to "turning the wheel of fortune." It may sound bizarre, but this "bed turning" action is still silently performed
}

in many hospitals today.

"After a patient dies, if the mattress is turned over, it tells the deceased spirit that the place he stayed in before has changed and that it is time to move on. Or otherwise the spirit of the deceased will take the life of the next patient, and the same thing will happen again and again..."

\section{Donotsay "seeyou later"("see again" in Chinese) upon parting in the hospital}

Nurses do not say"see you later" ("see again" in Chinese) when a patient is discharged. Visitors should also avoid saying "see you later" when leaving the hospital. They can only say "byebye", so as to avoid seeing the patient again in the future.

"When a patient is discharged, we always say 'bye-bye', so as to avoid seeing the patient again. If nurses said 'see you later', it can make the patient angry."

\section{The nurse's cap is a sign to keep demons away}

Back in the day when hospital nurses in Taiwan were still required to wear nurse caps, their seniors often reminded incoming nurses in a low voice.

"It's late and quiet. You'd better not remove your nurse caps!

It is said that nurse caps drive demons away."

Some timid nurses even brought their nurse caps back to their dormitory to keep evil spirits away. However, most nurses in Taiwan no longer wear nurse caps anymore.

\section{Hospital elevators skip the $4^{\text {th }}$ floor or the $4^{\text {th }}$ ward}

In Taiwan and most Chinese dialects (as in Japanese culture), the number " 4 " and "death" are homonyms that differ only in intonation. It is a dreaded number. Meanings of superstitions are passed on from one generation to another.

"Some patients do not like this number, so the most common aversion is to skip anything that has " 4 " in it. Hence, in Taiwan, many hospitals do not have a $4^{\text {th }}$ floor or a $4^{\text {th }}$ ward."

Not only hospitals, but hotels also will often skip numbers that end in 4 or change the $4 \mathrm{~F}$ to the $5 \mathrm{~F}$, and thus avoid using the number in public places. When buying and selling houses, the $4^{\text {th }}$ floor is sometimes the cheaper floor in a building. Sellers may avoid saying " 4 rooms", and will say " 3 rooms plus 1 "instead. These findings show that superstitious expectations, despite being irrational, can have a helpful force on cognition and behavior. The effects of suggestion can be powerful, but do not always work.

In summary, all countries havebelief about luck, depending on their external culture and workplace environment. When ever such beliefs appear in the hospital though, most nurses will "roll their eyes." This is because the hospital is where patients are taken care of and get better. Therefore, health care professionals need to be positive thinkers to deliver necessary support, both physical and mental, to their patients.

\section{Results and discussion}

Beliefs about luck were referred to legends. But now, supersti- 
tions generally require at least some sort of rational foundation that uses the interpretation of the contemporary state of knowledge. Day and Maltby (2005) found that belief in good luck was perceived as an important factor when individuals were planning their goals, alongside their intention to work towards a goal, and their own abilities and motivation regarding reaching that goal [16]. A similar finding can be presented in the current study with the general belief in luck subscale showing a positive correlation with externally caused emotions, problem avoidance, importance of the past, and the demands of irrational beliefs.

Most businesses expect booming performance, but this is not the case for hospitals. The word pineapple in the Taiwanese language is pronounced "own-lai" or "wang-lai", which has two meanings:'prosperity' and 'to come'. To nurses, prosperity is interpreted as patients having problems. Hence, in order to reduce the burden of work or for patients' conditions to stabilize, medical staff will often stay away from pineapples. An interesting study might also be the examination of thoughts and behaviors, such as not eating pineapple during on duty, that are intended to avoid unpredicted things. Researchers conducting an experimental study found that eating pineapples before work did not lead to "prosperity" during work shifts [28]. To the medical and nursing academia where empirical proof is all that matters, research results from "Pineapple Taboos: Myth or Reality" show that the number of clinical visits during pineapple season or non-season are almost the same. For ENT physicians who ate pineapples, compared to those that did not, the number of clinical visits also showed no significant difference [28]. In other words, staffs on duty have eaten pineapples that have no relation on increased workload. This phenomenon is even extended to "Wang Wang Rice Crackers." It is a taboo to place offerings with the character "wang" on the table during hospital worship rituals ("Putu" Festiva), and Wang Wang Rice Crackers is one of them.

Some medical and nursing staffs are seen as destined to be "unlucky", and these people are more likely than others to encounter patients with problems. Nurses all hope that no severe or acute things happen in the unit, no issues arise, and patients will not require procedures, etc. Patients coming rushing in would mean heavy workloads. Believing in one's own good fortune motivates people to take chances, and creates the opportunity for good fortune to lead to good results. The hospital is where life starts and ends. These beliefs are to ensure the stability of patients, as a surge of workload on the part of medical staff can also bring about unstable conditions in patients. Never say anything remotely close to the phrase "calm" or "not busy". It is a taboo subject among Taiwanese nurses. Similar phenomena in Vinson (1998) reported physicians avoiding mentioning the word "quiet" when there is low patient volume, for fear of triggering a subsequent rash of activity [7]. Each of these beliefs and behaviors is related with desired positive outcomes. Specifically, people anticipate doing well on a successive task. Whenever there is a shortage of manpower, being "busy" in the hospital signifies added workloads [29]. Perhaps the reason why the above has been labeled as added work burdens is that they are homonyms with either bringing good fortune or avoiding bad fortune.

Sociologists tested the power of the Chinese superstition linking the number 4 to death and stated that superstitions can raise stress and anxiety levels. Taboo homophone words are a sociolinguistic phenomenon common in Taiwanese culture [30]. Tse (2011) indicated the Chinese attitude towards taboo homophone words is a social phenomenon. Researchers were also keen to investigate peoples' attitudes towards taboo homophone words. Tse pointed out that because the number 4 has the identical pronunciation as the word 'death', people will generally see " 4 " as an unlucky number and tend to avoid it. People are concerned about staying on the $4^{\text {th }}$ floor in a hospital, and such beliefs can not only scare themselves but also others [31]. In some private hospitals in Hong Kong, few patients will stay on $4^{\text {th }}$ floor, so these hospitals charge less for wards on this floor. It is one of the people's ways of "homophonicly" avoiding misfortune in healthcare settings.

Some research is known about the superstitious beliefs and strategies in establishing control over uncertain circumstances [32]. Use of superstitious behaviors is thought to lead to greater levels of self-efficacy that result from 'superstition activation', and thus lead to higher self-set goals and greater persistence. Researchers have also reported that superstitions are psychologically motivated, and a method of dealing with a sense of lack of control [33]. Damisch et al., (2010) distinguished why these superstitions improved performance, and the researchers measured their self-efficacy and goal-setting [5]. Effort and ability are classified as part of the internal locus of control while task difficulty and luck are classified as external factors [34].

There are some major limitations of this study: the studies on the list were chosen based on internet discussion forum not on clinical workplace. They were selected based on researcher's social network.

\section{Conclusion}

Workplace-related beliefs about luck have little evidence in today's nursing science, but still appeal as a tonic to cope with hope, desire, fear, or anxiety. This study suggests that understanding the processes between beliefs about luck and workplace-related stress can affect outcomes. At any time, individuals can put chance on their side by managing risk in terms of determinable probabilities, thereby reducing the extent to which there is dependence on luck alone.

\section{Recommendations for practice}

Underlying these irrational beliefs are long-forgotten ways of thought that affect us still. However, we should not rely on luck, but instead practice an optimistic attitude and promote beliefs in internal locus of control. 
Lin et al. Journal of Nursing 2014,

http://www.hoajonline.com/journals/pdf/2056-9157-1-1.pdf

doi: $10.7243 / 2056-9157-1-1$

What does this paper contribute to the wider global clinical community?

1. This paper discovering nurses' viewpoints and cultural

ideals is important to understanding nursing practices.

2. These irrational beliefs are long-forgotten ways of thought that affect nurses still.

3. The findings indicate the stresses and coping behaviors of workplace that Taiwanese nurses'face when increased workload.

\section{Competing interests}

The authors declare that they have no competing interests.

\section{Authors' contributions}

\begin{tabular}{|l|c|c|c|}
\hline Authors' contributions & FYL & HRL & TYL \\
\hline Research concept and design & $\checkmark$ & -- & -- \\
\hline Collection and/or assembly of data & $\checkmark$ & -- & -- \\
\hline Data analysis and interpretation & $\checkmark$ & $\checkmark$ & $\checkmark$ \\
\hline Writing the article & $\checkmark$ & $\checkmark$ & $\checkmark$ \\
\hline Critical revision of the article & $\checkmark$ & $\checkmark$ & $\checkmark$ \\
\hline Final approval of article & $\checkmark$ & $\checkmark$ & $\checkmark$ \\
\hline Statistical analysis & -- & -- & -- \\
\hline
\end{tabular}

\section{Acknowledgement}

Special appreciations should be given to nurses, for the valuable information provided by them in their respective fields during the period of our study.

\section{Publication history}

Editors: M. Terese Verklan, UTMB Health School of Nursing, USA. Aru Narayanasamy, University of Nottingham, UK. Received: 18-Feb-2014 Final Revised: 07-Sep-2014 Accepted: 09-Sep-2014 Published: 24-Sep-2014

\section{References}

1. Day $L$ and Maltby J. Belief in good luck and psychological well-being: the mediating role of optimism and irrational beliefs. J Psychol. 2003; 137:99-110. | Article | PubMed

2. Darke P.R and Freedman J.L. Lucky events and beliefs in luck: Paradoxical effects on confidence and risk-taking. Personality and Social Psychology Bulletin. 1997; 23:378-388. | Article

3. Darke P.R and Freedman J.L. "The Belief in Good Luck Scale". Journal of Research in Personality. 1997; 31:486-511. | Pdf

4. Wiseman $R$ and Watt $C$. Measuring superstitious belief: Why lucky charms matter. Personality and Individual Differences. 2004; 37:15331541. | Article

5. Damisch L, Stoberock B and Mussweiler T. Keep your fingers crossed!: how superstition improves performance. Psychol Sci. 2010; 21:1014-20. | Article | PubMed

6. Shearer R and Davidhizar R. Luck: what the nurse should know about it and how it affects nursing situations. Int J Nurs Pract. 2000; 6:2-6. Article I PubMed

7. Vinson D.R. Change of shift. Superstitions in medicine: Bad luck or bad logic? Annals of Emergency Medicine. 1998; 31:650-652. | Article

8. Mandell DL, Claypool ML and Kay DJ. Superstitions among perioperative nurses. AORN J. 2005; 81: 983-984. | Article I PubMed

9. Schuld J, Slotta JE, Schuld S, Kollmar O, Schilling MK and Richter S. Popular belief meets surgical reality: impact of lunar phases, Friday the 13th and zodiac signs on emergency operations and intraoperative blood loss. World J Surg. 2011; 35:1945-9. | Article | PubMed

10. Keane EM, O'Leary P and Walsh JB. 'Saturday flit, short sit'--a strong influence of a superstition on the timing of hospital discharges? Ir Med J. 1997; 90:28. | PubMed

11. Krajewska-Kułak E, Kułak W, Radziejewski P, Rozwadowska E, Lankau A, Kowalewska B, Kondzior D, Szyszko-Perłowska A, Krajewska-Ferishah $\mathrm{K}$, Ortman $\mathrm{E}$ and Moczydłowska A. Current view of the traditional superstitions in general population of Podlaskie province. Preliminary study, Progress in Health Science. 2011; 1:76-83. I Pdf

12. Kumar VV, Kumar NV and Isaacson G. Superstition and posttonsillectomy hemorrhage. Laryngoscope. 2004; 114:2031-3. | Article | PubMed

13. Szasz P. The role of irrational beliefs, brooding and reflective pondering in predicting distress. Journal of Cognitive \& Behavioral Psychotherapies. 2011; 11:43-55. | Article

14. Kirsch I. Response expectancy as a determinant of experience and behavior. American Psychologist. 1985; 40:1189-1202. | Article

15. Michael R. B, Garry M and Kirsch I. Suggestion, Cognition, and Behavior. Current Directions in Psychological Science. 2012; 21:151-156. | Article

16. Day L and Maltby J. "With good luck": Belief in good luck and cognitive planning. Personality and Individual Differences. 2005; 39:1217-1226. | Article

17. Keinan $\mathrm{G}$. The effects of stress and desire for control on superstitious behavior. Personality and Social Psychology Bulletin. 2002; 28:102-108. I Article

18. Schippers M.C and Van Lange P.A.M. The psychological benefits of superstitious rituals in top sport: A study among top sportspersons. Journal of Applied Social Psychology. 2006; 36:2532-2553. | Article

19. Zhang Y, Risen JL and Hosey C. Reversing one's fortune by pushing away bad luck. J Exp Psychol Gen. 2014; 143:1171-84. | Article | PubMed

20. Foster KR and Kokko $H$. The evolution of superstitious and superstitionlike behaviour. Proc Biol Sci. 2009; 276:31-7. I Article | PubMed Abstract I PubMed Full Text

21. Andre N. Good fortune, luck, opportunity and their lack. How do agents perceive them? Personality and Individual Differences. 2006; 40:14611472. | Article

22. Maltby J, Day L, Gill P, Colley A and Wood A.M. Beliefs around luck: confirming the empirical conceptualization of beliefs around luck and the development of the Darke and Freedman beliefs around luck scale. Personality and Individual Differences. 2008; 45:655-660. | Article

23. Fluke SM, Webster RJ and Saucier DA. Methodological and theoretical improvements in the study of superstitious beliefs and behaviour. $\mathrm{Br} J$ Psychol. 2014; 105:102-26. | Article | PubMed

24. Lindeman M and Svedholm A. M. What's in a term? Paranormal, superstitious, magical and supernatural beliefs by any other name would mean the same. Review of General Psychology. 2012; 16:241-255. I Article

25. Hewson C. Conducting research on the Internet. The Psychologist. 2003; 16:290-293. | Pdf

26. Steinmetz S, Kaczmirek L, Pedraza P, Reips U.D, Tijdens K, Lozar Manfreda $K$ and Winer B. Web data net: A network on web-based data collection, methodological challenges, solutions and implementation. International Journal of Internet Science. 2012; 7:78-89. I Pdf

27. Elo $\mathrm{S}$ and Kyngas $\mathrm{H}$. The qualitative content analysis process. J Adv Nurs. 2008; 62:107-15. | Article | PubMed

28. Chien S.H. Taboos of pineapple: myth or reality. Taiwan Medical Journal. 2012; 55:21-23.

29. Tanz RR and Charrow J. Black clouds. Work load, sleep, and resident reputation. Am J Dis Child. 1993; 147:579-84. | Article | PubMed

30. Phillips DP, Liu GC, Kwok K, Jarvinen JR, Zhang W and Abramson IS. The Hound of the Baskervilles effect: natural experiment on the influence of psychological stress on timing of death. BMJ. 2001; 323:1443-6. | Article | PubMed Abstract | PubMed Full Text

31. Tse A.Y.H. Linguistic word taboos in Chinese culture. British Journal of Humanities and Social Sciences. 2011; 1:134-145. | Pdf 
Lin et al. Journal of Nursing 2014,

http://www.hoajonline.com/journals/pdf/2056-9157-1-1.pdf

32. Case T.I, Fitness J, Cairns D.R and Stevenson R.J. Coping with uncertainty: Superstitious strategies and secondary control. Journal of Applied Social Psychology. 2004; 34:848-871. | Article

33. Wright $P$ and Erdal K. Sport superstition as a function of skill level and task difficulty. Journal of Sport Behavior. 2008; 31:187-199. | Article

34. Rotter J. Some problems and misconceptions related to the construct of internal versus external control of reinforcement. Journal of Consulting and Clinical Psychology. 1975; 43:56-67. | Article

\section{Citation:}

Lin F-Y, Lin H-R and Lee T-Y. Workplace beliefs about

luck among taiwanese nurses. J Nurs. 2014; 1:1.

http://dx.doi.org/10.7243/2056-9157-1-1 